\section{Guanosine triphosphate acts as a cofactor to promote assembly of initial P-element transposase-DNA synaptic complexes}

\author{
Mei Tang, ${ }^{1}$ Ciro Cecconi ${ }^{2,4}$ Helen Kim, ${ }^{1}$ \\ Carlos Bustamante, ${ }^{1,2,3,4}$ and Donald C. Rio ${ }^{1,5}$ \\ ${ }^{1}$ Department of Molecular and Cell Biology, Division of \\ Genetics, Genomics and Development and Division of \\ Biochemistry and Molecular Biology, Center for Integrative \\ Genomics, and ${ }^{2}$ Department of Physics, University of \\ California, Berkeley, California 94720, USA; ${ }^{3}$ Howard Hughes \\ Medical Institute, University of California, Berkeley, CA \\ 94720, USA; ${ }^{4}$ Lawrence Berkeley National Laboratory, \\ Berkeley, California 94720, USA
}

$P$ transposable elements in Drosophila are members of a larger class of mobile elements that move using a cutand-paste mechanism. P-element transposase uses guanosine triphosphate (GTP) as a cofactor for transposition. Here, we use atomic force microscopy (AFM) to visualize protein-DNA complexes formed during the initial stages of P-element transposition. These studies reveal that GTP acts to promote assembly of the first detectable noncovalent precleavage synaptic complex. This initial complex then randomly and independently cleaves each P-element end. These data show that GTP acts to promote protein-DNA assembly, and may explain why $P$ element excision often leads to unidirectional deletions.

Received March 23, 2005; revised version accepted April 22, 2005.

Transposable elements are ubiquitous mobile DNA segments found in both prokaryotic and eukaryotic organisms (Craig et al. 2002). Mobile elements are now known to make up major portions of eukaryotic genomes, including the human genome (Lander et al. 2001; Venter et al. 2001). Because these elements are thought to be an avenue for mutation, genome rearrangements, and genome evolution (Curcio and Derbyshire 2003; Kazazian 2004), there has been intense interest in the mechanisms by which these DNA segments are mobilized. Transposons are broadly classified into two categories based upon whether there is a DNA or an RNA intermediate (Craig et al. 2002). P elements fall into the class of mobile elements that transpose via a DNA intermediate that uses a cut-and-paste mechanism, similar to the prokaryotic transposons Tn5, Tn10, and Tn7 and the eukaryotic Tc1/mariner family of elements (Engels 1989;

[Keywords: DNA-binding proteins; DNA rearrangements; GTP-binding proteins; protein-DNA complexes; transposition]

${ }^{5}$ Corresponding author.

E-MAIL don_rio@berkeley.edu; FAX (510) 642-6062.

Article and publication are at http://www.genesdev.org/cgi/doi/10.1101/ gad.1317605.
Craig 1995; Rio 2002). Biochemical studies have shown that P-element transposition requires both guanosine triphosphate (GTP) and magnesium ions $\left(\mathrm{Mg}^{2+}\right)$ as cofactors (Kaufman and Rio 1992; Beall and Rio 1997; Mul and Rio 1997; Rio 2002). Furthermore, nonhydrolyzable GTP analogs fully substitute for GTP in both the donor cleavage and strand transfer reactions (Kaufman and Rio 1992). While all known transposase proteins use a metal ion cofactor (Rice and Baker 2001; Craig et al. 2002; Gellert 2002), the use of GTP in the P-element reaction is unique among this family of polynucleotidyl transferases. GTP is known to serve as a cofactor in many diverse biochemical processes, such as the ras superfamily of small GTPases (Bourne et al. 1990, 1991), the assembly of the dynamin family of vesicle transport proteins (Margolin 2000; Song and Schmid 2003; Praefcke and McMahon 2004), the assembly of tubulin into microtubules (Nogales et al. 2003), protein translation on the ribosome (Spirin 2002), and the self-splicing of group I introns (Cech 1990; Doudna and Cech 2002). Thus, it has been of interest to understand the role of GTP in P-element transposition.

Like other transposition reactions, the P-element transposes via a two-step reaction (Craig 1995) in which, initially, the two ends of the transposon are cleaved from the flanking DNA (donor cleavage) and, subsequently, the excised transposon intermediate captures and integrates into a target DNA site (strand transfer) (Fig. 1A). Attempts to detect P-element transposase-DNA complexes using native gel electrophoresis proved unsuccessful, and we turned to the method of atomic force microscopy (AFM) to visualize and quantitate P-element reaction products and intermediates formed during transposition. This method has been used to analyze protein-DNA complexes involved in transcription and DNA repair (Wyman et al. 1997; de Jager et al. 2001). Here, we show that the role of GTP is to promote formation of synaptic complexes with both P-element ends prior to DNA cleavage. Cleavage at the P-element ends is not coordinated, with each end being randomly and independently cleaved. These findings illuminate the role GTP plays in P-element transposition and may explain why unidirectional deletions are observed following Pelement excision.

\section{Results and Discussion}

Using tapping-mode AFM, initial experiments were performed using purified P-element transposase (Fig. 1B) and a linear DNA fragment carrying a 0.6-kb P element located asymmetrically in the DNA with flanking regions of 0.3 and $0.6 \mathrm{~kb}$ (Fig. 2A, top). This natural 0.6-kb $\mathrm{P}$ element was active in vivo for transposition into the white locus (O'Hare and Rubin 1983). However, it should be noted that the $0.6-\mathrm{kb} \mathrm{P}$ element used here is much smaller than the 2.9-kb full-length autonomous element, but that in natural P-strain flies, $\mathrm{P}$ elements from 0.5 to $2.9 \mathrm{~kb}$ exist and can be mobilized (Engels 1989; Rio 2002). These reactions were performed in the presence of the cofactors GTP and $\mathrm{Mg}^{2+}$ at levels known to be optimal for both excision and strand transfer in vitro. In these reactions, four types of molecules were observed. First, we observed loops with tails, held together by a protein knob (Fig. 2B). Measurement of these 
A



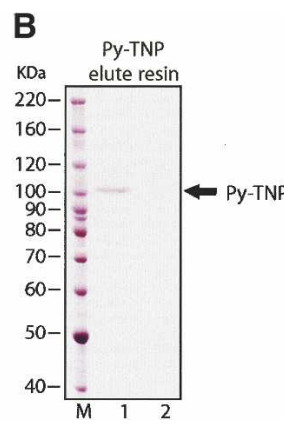

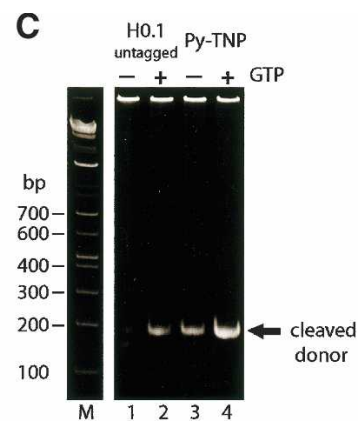

Figure 1. The P-element transposition reaction. (A) P-element transposition takes place in two stages, donor cleavage and target joining or integration. Following DNA repair, a new P-element insertion is created. (B) SDS-polyacrylamide gel electrophoresis analysis of purifed P-element transposase after elution indicated by arrow (lane 1), and the resin after elution (lane 2), stained with Coomassie blue. Lane $M$ is protein molecular weight standards, indicated in kilodaltons at left. (C) LM-PCR assay for donor DNA cleavage at the P-element ends analyzed by polyacrylamide gel electrophoresis using untagged transposase (H0.1) (lanes 1,2) or the 3' Py-tagged transposase (lanes 3,4), either with $(+)$ or without (-) added GTP. Lane $M$ is a 100-bp DNA marker, indicated in base pairs at left.

tail lengths indicated that these molecules were synaptic complexes in which P-element transposase had brought the two P-element ends together. Second, we observed loops with one tail, either the long or short one, consistent with cleavage of one P-element end without coordinated cleavage of the other end (Fig. 2C,D). Third, there were circular molecules held together by a protein knob that were measured to be $0.6 \mathrm{~kb}$, the size of the excised P element (Fig. 2E). Molecules of these types were not observed in the absence of P-element transposase or when a non-P-element DNA fragment of similar length was used indicating the specificity of proteinDNA complex assembly and the dependence on terminal P-element DNA sequences (data not shown).

In order to investigate the role of GTP in the P-element transposition reaction and the relationships among the various structures observed, we performed timecourse experiments in the presence and absence of GTP and quantitated the number of each type of molecule at time points from 0.5 to $26 \mathrm{~h}$ (Figs. 3, 4). These experiments show that GTP acts as a cofactor to stimulate the assembly of the initial noncovalent synaptic complex between the P-element transposase and the P-element DNA ends. In the absence of GTP, loops with two tails were observed with a low frequency $(<1 \%)$ at early time points, but accumulated to some extent $(\sim 7 \%)$ after $26 \mathrm{~h}$ (Fig. 3A). We believe that the activity responsible for the slow accumulation of this product is due to residual GTP bound to a fraction of the purified P-element transposase, as indicated from activity assays (see Fig. 1C). In contrast, when reactions were carried out in the presence of $2 \mathrm{mM}$ GTP, there was a rapid accumulation of Pelement synaptic complexes (Fig. 3B). At the 0.5-h time point, there are $\sim 7 \%$ synaptic complexes (loops with tails), and these complexes appear to go away with time, consistent with them being the initial complexes that subsequently react to cleave the P-element ends away from the flanking donor DNA. These observations indicate that GTP acts as an allosteric effector to promote specific DNA-protein synaptic complex formation. When GTP is added to transposase, in the absence of P-element DNA, no change in the oligomerization state or apparent size of the protein was observed (data not shown).

Next, we measured the abundance of partially cleaved products with either a long tail or a short tail (Fig. 4A-D). In the absence of GTP, both types of molecules accumulated slowly in time and to a similar extent over the time course of the reaction (Fig. 4A,C). In contrast, in the presence of GTP, these molecules accumulated more rapidly, peaking at $3 \mathrm{~h}$, and then decaying at the longest time point sampled, $26 \mathrm{~h}$ (Fig. 4B,D). These observations are consistent with the single-ended cleavage products being intermediates in the reaction, which then give rise to the doubly cleaved circular molecules (Fig. 2E). Interestingly, because both the long- and short-tailed molecules follow similar kinetics and are very similar in abundance (Fig. 4B,D), each P-element end appears to be cleaved independently and randomly during the donor cleavage reaction with release of the flanking donor DNA duplex. Thus, there is not a concerted reaction in which cleavage of both P-element ends is coupled. These findings may also explain why in vivo, following P-element excision, deletions of DNA sequences flanking the P-element insertion site are often unidirectional (Engels 1989; Adams and Sekelsky 2002; Rio 2002). The released donor DNA end might be subject to nucleolytic degradation prior to entering the DNA repair pathway(s), thus giving rise to the observed flanking deletions.

A

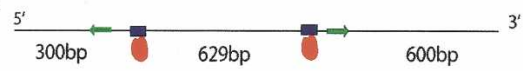

B pre-cleavage synaptic complex


C

single cleavage complex


D single cleavage complex
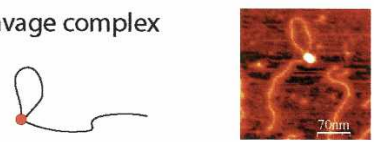

E

cleaved donor complex


Figure 2. Visualization of P-element transposase protein-DNA complexes. (A) Diagram of the P element containing substrate DNA frament. A 629-bp P element is flanked by 300 and 600 bp, respectively, at each end. P-element 31-bp terminal inverted repeats and the transposase-binding sites are indicated, as is the transposase protein (spheres). (B) Precleavage synaptic complex (loop with two tails). $(C, D)$ Intermediate single-cleavage products; loop with short tail $(C)$ or loop with long tail $(D) .(E)$ Cleaved donor complex; circles with a protein "knob". The $Y$-axis values were generated by using the indicated percentage of complexes (loops with tails) compared with the total of measured full-length DNA molecules (with or without protein bound) visualized under AFM. The experiment was repeated three times, and the experimental variations were shown with standard deviation error bars. 
The circular cleaved donor DNA complexes /circles without tails) were also quantitated as a function of time in the presence or absence of GTP (Fig. 4E,F). In the absence of GTP, very few circular complexes accumulated with time (Fig. 4E). In contrast, in the presence of GTP, these doubly cleaved excised transposon complexes accumulated as a function of time and appeared to be stable, because at the last 26-h time point, they represent $\sim 13 \%$ of the total DNA molecules in the population. The stability of these excised complexes with the transposase may explain why in vivo, the P-element excision frequency is greater than the excision and reinsertion frequency (Engels 1989; Rio 2002). At the last 26-h time point, several molecules in which the circular complexes have apparently captured a target DNA were observed (data not shown). Thus, the capture of target DNA by the stable cleaved donor complexes may be slow, possibly requiring a conformational change to reposition the $\mathrm{P}$ element DNA termini or to generate a new DNA-binding site into which the target DNA would dock. It is also possible that in these reactions, P-element DNA is a poor target for insertion.

$\mathrm{P}$ elements are unusual as the only member of the transposase/integrase family to use GTP as a cofactor (Craig et al. 2002). Previous studies showed that GTP or any of three commonly used nonhydrolyzable GTP analogs supported both the donor cleavage and strand transfer reactions carried out by P-element transposase in vitro (Kaufman and Rio 1992). Here, we show that GTP promotes assembly of the earliest noncovalent complex of transposase with P-element DNA, in which the ends of the transposon DNA are synapsed. GTP is also known to modulate assembly of other proteins, such as dynamin (Margolin 2000; Song and Schmid 2003; Praefcke and McMahon 2004), tubulin (Nogales et al. 2003), and the bacterial restriction endonuclease McrBC (Panne et al. 2001). Interestingly, GTP was recently implicated in preventing a transposition reaction by a potential reaction with the RAG1 subunit of the V(D)J recombinase (Tsai and Schatz 2003). While the role of GTP in the V(D)J reaction is not clear, the $\mathrm{C}$ terminus of RAG2 appears to be capable of performing the same, or a similar, function (Elkin et al. 2003; Tsai and Schatz 2003). Thus, unlike any of the other members of the transposase/integrase family, P elements use GTP to modulate the assembly of catalytically active nucleoprotein complexes. Finally, we do not know whether P-element transposase can hydrolyze GTP. This activity has not been detected using

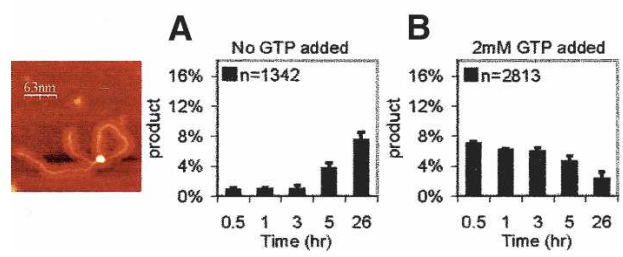

Figure 3. Quantitation of precleavage synaptic complexes (loops with two tails). (A) Time course $0.5-26$ h, no GTP added; $n=1342$ total molecules counted. $(B)$ Time course $0.5-26 \mathrm{~h}, 2 \mathrm{mM}$ GTP added; $n=2813$ total molecules counted. The $Y$-axis value was generated by using percentage of indicated complexes (short tail, long tail, or circles) as a fraction of the total full-length DNA molecules visualized under AFM. The experiment was repeated three times, and the experimental variations were shown with standard deviation error bars.
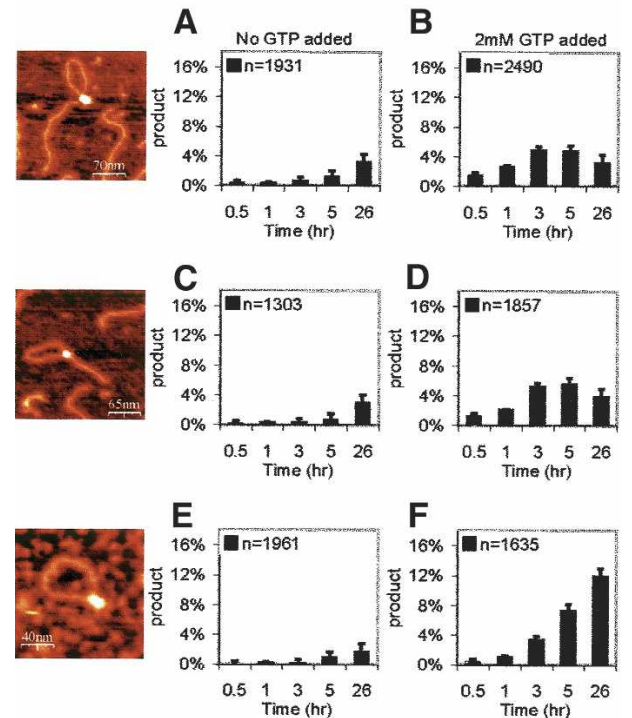

Figure 4. Quantitation of post-cleavage synaptic complexes. $(A-D)$ Intermediate single-cleavage complexes (loops with one tail). $(A)$ Loop with one long tail; time course $0.5-26 \mathrm{~h}$, no GTP added; $n=1931$ total molecules counted. $(B)$ Loop with one long tail; time course $0.5-26 \mathrm{~h}, 2 \mathrm{mM}$ GTP added; $n=2490$ total molecules counted. $(C)$ Loop with one short tail; time course $0.5-26$ h, no GTP added; $n=1303$ total molecules counted. $(D)$ Loop with one short tail; time course $0.5-26$ h, 2 mM GTP added; $n=1857$ total molecules counted. $(E, F)$ Cleaved donor complexes (circles with protein "knob". (E) Cleaved donor complexes (circles with protein "knob"); time course 0.5-26 h, no GTP added; $n=1961$ total molecules counted. (F) Cleaved donor complexe (circles with protein "knob"); time course $0.5-26$ h, 2 mM GTP added; $n=1635$ total molecules counted.

standard assays with or without DNA present. However, it might be the case that hydrolysis could be used to disassemble strand transfer complexes and recycle the protein. This type of mechanism is commonly used by GTP and ATP hydrolytic enzymes, for instance, in membrane vesicle fusion (Song and Schmid 2003; Praefcke and McMahon 2004), microtubule disassembly (Nogales et al. 2003), and DNA topoisomerase recycling (Corbett and Berger 2004). Future AFM studies should provide insight into the role played by GTP and its possible hydrolysis in the later stages of the P-element transposition reaction cycle.

\section{Materials and methods}

Protein purification and excision activity assay

P-element transposase tagged at its $\mathrm{C}$ terminus was purified using peptide elution from a polyoma (glu-glu) monoclonal antibody column as described (Porfiri et al. 1995; Rubinfeld and Polakis 1995; Mul and Rio 1997). Untagged transposase was purified using heparin-agarose and DNA affinity chromatography as described (Kaufman and Rio 1992; Beall and Rio 1997, 1998). LM-PCR assays to detect donor DNA cleavage at the P-element ends were performed as described (Beall and Rio 1997).

\section{DNA preparation}

Linear DNA excision substrate was amplified by PCR from the plasmid pISP-2/Km using Vent DNA polymerase (New England Biolabs). The DNA substrate, containing a 0.6 -kb P element flanked by either 0.3 or 0.6 $\mathrm{kb}$ of adjacent non-P-element DNA, was then purified from an agarose gel using a Qiagen purification kit.

Excision reaction

P-element donor cleavage reactions were carried out by mixing $1 \mu \mathrm{L}$ of purified 3'Py-TNP $(\sim 50 \mu \mathrm{g} / \mathrm{mL})$ in HGKED buffer ( $25 \mathrm{mM}$ Hepes-KOH at 
pH 7.6, 20\% glycerol, 0.5 mM DTT, 1 mM EDTA, 1 mM PMSF, 0.4 $\mathrm{MKCl}$ ) with $1 \mu \mathrm{L}$ of $40 \mathrm{nM}$ P-element donor DNA in $4 \mu \mathrm{L}$ of HGED buffer (25 mM Hepes- $\mathrm{KOH}$ at $\mathrm{pH}$ 7.6, 20\% glycerol, 0.5 mM DTT, 1 mM EDTA, $1 \mathrm{mM}$ PMSF). After incubation on ice for $10 \mathrm{~min}$, the mixture was added to $14 \mu \mathrm{L}$ of $10 \mathrm{mM} \mathrm{Mg}(\mathrm{OAc})_{2}$ in HGED buffer, with or without $2 \mathrm{mM}$ GTP, and incubated at $30^{\circ} \mathrm{C}$ for the indicated times. These reaction conditions are similar to those used previously for donor cleavage and strand transfer in bulk solution reactions (Kaufman and Rio 1992; Beall and Rio 1997, 1998).

Atomic force microscopy

Following incubation, $10 \mu \mathrm{L}$ of cleavage reaction was diluted with $10 \mu \mathrm{L}$ of AFM imaging buffer $\left(15 \mathrm{mM} \mathrm{MgCl}_{2}, 10 \mathrm{mM} \mathrm{KCl}, 5 \mathrm{mM}\right.$ Hepes-KOH at $\mathrm{pH}$ 7.6) and deposited on freshly cleaved mica for $1 \mathrm{~min}$ at room temperature. The mica was then gently washed with $\mathrm{ddH}_{2} \mathrm{O}$ and subsequently dried with nitrogen. The sample was imaged in air with a NanoScope III (Digital Instruments) atomic force microscope, operating in tapping mode, using tips from Nanosensors (pointprobes, type $\mathrm{NCH}$ 100). The AFM images were processed and analyzed using WSxM software (Nanotec Electronica). Specifically, the length of the full-size starting substrate DNA (1.5 kb) was measured by AFM using the software WSxM (Nanotec, Inc.) and the average base-pair length obtained was $0.335 \mathrm{~nm}$ with a standard error of $96 \% \pm 5 \%$. The average measurements of circles, short tail, and long tail molecules showed $5.59 \%, 9.08 \%$, and $8.07 \%$ variation, respectively, and accordingly, yielded accuracies of $94.8 \%, 100.9 \%$, and $98.5 \%$. The cut-off criterion for selecting complexes to score was using DNA measurements within $\pm 12 \%$ variation from the predicted size values.

\section{Acknowledgments}

We thank members of the Rio lab for suggestions and advice throughout the course of this work. This work was supported by NIH R01 GM48862.

\section{References}

Adams, M.D. and Sekelsky, J.J. 2002. From sequence to phenotype: Reverse genetics in Drosophila melanogaster. Nat. Rev. Genet. 3: 189198.

Beall, E.L. and Rio, D.C. 1997. Drosophila P-element transposase is a novel site-specific endonuclease. Genes \& Dev. 11: 2137-2151.

- 1998. Transposase makes critical contacts with, and is stimulated by, single-stranded DNA at the $\mathrm{P}$ element termini in vitro. EMBO J. 17: 2122-2136.

Bourne, H.R., Sanders, D.A., and McCormick, F. 1990. The GTPase superfamily: A conserved switch for diverse cell functions. Nature 348: $125-132$.

- 1991. The GTPase superfamily: Conserved structure and molecular mechanism. Nature 349: 117-127.

Cech, T.R. 1990. Self-splicing of group I introns. Annu. Rev. Biochem. 59: 543-568.

Corbett, K.D. and Berger, J.M. 2004. Structure, molecular mechanisms, and evolutionary relationships in DNA topoisomerases. Annu. Rev. Biophys Biomol. Struct. 33: 95-118.

Craig, N.L. 1995. Unity in transposition reactions. Science 270: 253-254.

Craig, N.L., Cragie, R., Gellert, M., and Lambowitz, A.M., eds. 2002. Mobile DNA II. American Society for Microbiology, Washington, DC.

Curcio, M.J. and Derbyshire, K.M. 2003. The outs and ins of transposition: From mu to kangaroo. Nat. Rev. Mol. Cell. Biol. 4: 865-877.

de Jager, M., van Noort, J., van Gent, D.C., Dekker, C., Kanaar, R., and Wyman, C. 2001. Human Rad50/Mre11 is a flexible complex that can tether DNA ends. Mol. Cell 8: 1129-1135.

Doudna, J.A. and Cech, T.R. 2002. The chemical repertoire of natural ribozymes. Nature 418: 222-228.

Elkin, S.K., Matthews, A.G., and Oettinger, M.A. 2003. The C-terminal portion of RAG2 protects against transposition in vitro. EMBO J. 22: 1931-1938.

Engels, W.R. 1989. P elements in Drosophila melanogaster. In Mobile DNA (eds. D.E. Berg and M.M. Howe), pp. 437-484. American Soc. Microbiol., Washington D.C.

Gellert, M. 2002. V(D)J recombination: RAG proteins, repair factors, and regulation. Annu. Rev. Biochem. 71: 101-132.
Kaufman, P.D. and Rio, D.C. 1992. P element transposition in vitro proceeds by a cut-and-paste mechanism and uses GTP as a cofactor. Cell 69: 27-39.

Kazazian Jr., H.H. 2004. Mobile elements: Drivers of genome evolution. Science 303: 1626-1632.

Lander, E.S., Linton, L.M., Birren, B., Nusbaum, C., Zody, M.C., Baldwin, J., Devon, K., Dewar, K., Doyle, M., FitzHugh, W., et al. 2001. Initial sequencing and analysis of the human genome. Nature 409: 860-921.

Margolin, W. 2000. Organelle division: Self-assembling GTPase caught in the middle. Curr. Biol. 10: R328-R330.

Mul, Y.M. and Rio, D.C. 1997. Reprogramming the purine nucleotide cofactor requirement of Drosophila $\mathrm{P}$ element transposase in vivo. EMBO J. 16: 4441-4447.

Nogales, E., Wang, H.W., and Niederstrasser, H. 2003. Tubulin rings: Which way do they curve? Curr. Opin. Struct. Biol. 13: 256-261.

O'Hare, K. and Rubin, G.M. 1983. Structures of $P$ transposable elements and their sites of insertion and excision in the Drosophila melanogaster genome. Cell 34: 25-35.

Panne, D., Muller, S.A., Wirtz, S., Engel, A., and Bickle, T.A. 2001. The McrBC restriction endonuclease assembles into a ring structure in the presence of G nucleotides. EMBO J. 20: 3210-3217.

Porfiri, E., Evans, T., Bollag, G., Clark, R., and Hancock, J.F. 1995. Purification of baculovirus-expressed recombinant Ras and Rap proteins. Methods Enzymol. 255: 13-21.

Praefcke, G.J. and McMahon, H.T. 2004. The dynamin superfamily: Universal membrane tubulation and fission molecules? Nat. Rev. Mol. Cell. Biol. 5: 133-147.

Rice, P.A. and Baker, T.A. 2001. Comparative architecture of transposase and integrase complexes. Nat. Struct. Biol. 8: 302-307.

Rio, D.C. 2002. P transposable elements in Drosophila melanogaster. In Mobile DNA II (eds. N.L. Craig, et al.), pp. 484-518. American Society for Microbiology, Washington, DC.

Rubinfeld, B. and Polakis, P. 1995. Purification of baculovirus-produced Rapl GTPase-activating protein. Methods Enzymol. 255: 31-38.

Song, B.D. and Schmid, S.L. 2003. A molecular motor or a regulator? Dynamin's in a class of its own. Biochemistry 42: 1369-1376.

Spirin, A.S. 2002. Ribosome as a molecular machine. FEBS Lett. 514: $2-10$.

Tsai, C.L. and Schatz, D.G. 2003. Regulation of RAG1/RAG2-mediated transposition by GTP and the C-terminal region of RAG2. EMBO $J$. 22: 1922-1930

Venter, J.C., Adams, M.D., Myers, E.W., Li, P.W., Mural, R.J., Sutton, G.G., Smith, H.O., Yandell, M., Evans, C.A., Holt, R.A., et al. 2001. The sequence of the human genome. Science 291: 1304-1351.

Wyman, C., Rombel, I., North, A.K., Bustamante, C., and Kustu, S. 1997. Unusual oligomerization required for activity of NtrC, a bacterial enhancer-binding protein. Science 275: 1658-1661. 


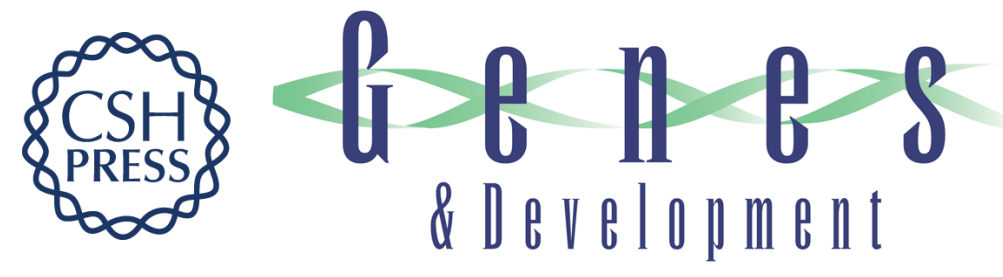

\section{Guanosine triphosphate acts as a cofactor to promote assembly of initial P-element transposase-DNA synaptic complexes}

Mei Tang, Ciro Cecconi, Helen Kim, et al.

Genes Dev. 2005, 19:

Access the most recent version at doi:10.1101/gad.1317605

References

This article cites 29 articles, 8 of which can be accessed free at:

http://genesdev.cshlp.org/content/19/12/1422.full.html\#ref-list-1

License

Email Alerting

Receive free email alerts when new articles cite this article - sign up in the box at the top

Service right corner of the article or click here.

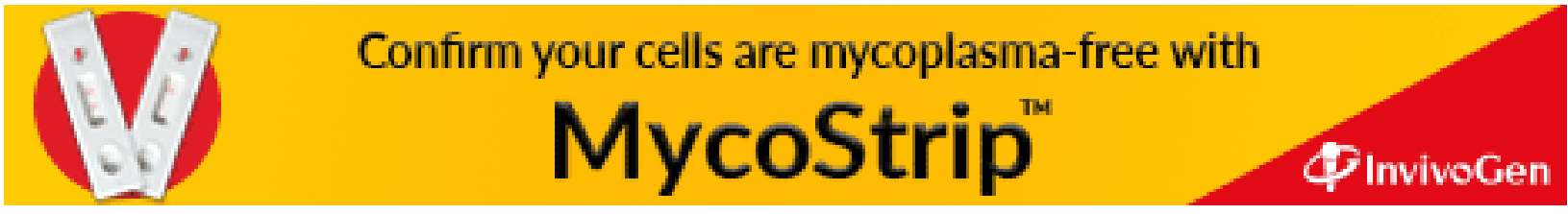

